\title{
Salmonelose Aviária
}

\author{
A vian Salmonellosis \\ Salmonelosis Aviar
}

\section{Resumo}

A salmonelose aviária é um termo usado para se referir aos três tipos diferentes de doenças bacterianas causadas pelo gênero Salmonella sp (pulorose, tifo aviário e paratifo aviário) nas aves domésticas. A pulorose tem sua etiologia relacionada à Salmonella pullorum, o tifo aviário à Salmonella gallinarum e o paratifo aviário a todos os demais sorotipos patogênicos entéricos. As três doenças podem acometer aves domésticas de qualquer idade causando sinais clínicos inespecíficos e sistêmicos, com quadros agudos e crônicos que podem ser confundidos com outras bacterioses. Mundialmente disseminadas, essas doenças são responsáveis por causar impactos na economia brasileira e na saúde pública. A transmissão pode ocorrer pela via vertical e horizontal e pelo contato indireto com alimentos, água de beber, vetores e fômites contaminados. O diagnóstico das aves doentes pode ser realizado com base no histórico, sinais clínicos, achados anatomopatólogicos e exames laboratoriais que incluem a identificação dos agentes por meio de isolamento bacteriano, soroaglutinação rápida em placas, soroaglutinação lenta em tubos e reação em cadeia da polimerase (PCR). Como não há tratamento antibiótico que elimine completamente a infecção nas aves as medidas de controle e prevenção são indispensáveis no controle. O presente artigo trata-se de uma revisão de literatura e tem como objetivo conhecer o referencial teórico referente à doença e aos seus agentes, além da possibilidade de esclarecer a importância da prevenção e do controle desse microrganismo, devido ao caráter infectocontagioso e zoonótico da doença, que pode causar inúmeros prejuízos econômicos e impactos negativos para a saúde pública.

Palavras-chave: Salmonelose aviária; Frango; Avicultura.

\begin{abstract}
Avian salmonellosis is a term used to refer to the three different types of bacterial diseases caused by the genus Salmonella sp (pulorosis, avian typhus and avian paratyph) in domestic birds. Pulorosis has its etiology related to Salmonella pullorum, avian typhus to Salmonella gallinarum and avian paratyph to all other enteric pathogenic serotypes. The three diseases can affect domestic birds of any age, causing unspecific and systemic clinical signs, with acute and chronic conditions that can be confused with other bacteriosis. Worldwide, these diseases are responsible for impacting the Brazilian economy and public health. Transmission can occur via vertical and horizontal routes and indirect contact with contaminated food, drinking water, vectors and fomites. The diagnosis of sick birds can be performed based on history, clinical signs, anatomopathological findings and laboratory tests that include the identification of agents by bacterial isolation, rapid serum agglutination in plates, slow serum agglutination in tubes
\end{abstract}


and polymerase chain reaction (PCR ). As there is no antibiotic treatment that completely eliminates the infection in birds, control and prevention measures are indispensable in the control of these diseases. This article is a literature review and aims to know the theoretical framework for the disease and its agents, in addition to the possibility of clarifying the importance of prevention and control of this microorganism, due to the infectious and zoonotic nature of the disease, which can cause numerous economic losses and also negative impacts on public health.

Keywords: Avian salmonellosis; Chicken; Poultry.

\section{Resumen}

La salmonelosis aviar es un término utilizado para referirse a los tres tipos diferentes de enfermedades bacterianas causadas por el género Salmonella sp (pulorosis, tifus aviar y paratifo aviar) en aves domésticas. La pulorosis tiene su etiología relacionada con Salmonella pullorum, el tifus aviar con Salmonella gallinarum y el paratifoide aviar con todos los demás serotipos patógenos entéricos. Las tres enfermedades pueden afectar a aves domésticas de cualquier edad, provocando signos clínicos inespecíficos y sistémicos, con condiciones agudas y crónicas que pueden confundirse con otras bacteriosis. A nivel mundial, estas enfermedades son responsables de impactar la economía y la salud pública brasileñas. La transmisión puede ocurrir por rutas verticales y horizontales y el contacto indirecto con alimentos contaminados, água potable, vectores y fómites. El diagnóstico de aves enfermas se puede realizar en base a la história, signos clínicos, hallazgos anatomopatológicos y pruebas de laboratorio que incluyen la identificación de agentes mediante aislamiento bacteriano, aglutinación sérica rápida en placas, aglutinación sérica lenta en tubos y reacción en cadena de la polimerasa (PCR). Como no existe un tratamiento antibiótico que elimine por completo la infección en las aves, las medidas de control y prevención son indispensables en el control de estas enfermedades. Este artículo es una revisión de la literatura y tiene como objetivo conocer el marco teórico de la enfermedad y sus agentes, además de la posibilidad de esclarecer el importancia de la prevención y el control de este microorganismo, debido al carácter infeccioso y zoonótico de la enfermedad, que puede ocasionar numerosas pérdidas económicas y también impactos negativos en la salud pública.

Palabras clave: Salmonelosis aviar; Pollo; Avicultura.

\section{Introdução}

Para a atividade avícola brasileira se manter internacionalizada, é necessário o emprego de medidas rigorosas de controle e prevenção, contra agentes que causam enfermidades infecciosas em aves de produção, bem como surtos alimentares em humanos. Na avicultura comercial, as bactérias do gênero Salmonella sp. tem uma grande importância, pois com a expansão do mercado baseada em uma avicultura intensiva, os animais são alojados em grandes concentrações, favorecendo a propagação desses microrganismos. A enfermidade nas aves, provocada pelas bactérias do gênero Salmonella sp., é conhecida como salmonelose aviária. Os principais agentes etiológicos envolvidos são a Salmonella pullorum, Salmonella gallinarum, Salmonella enteritides e a Salmonella typhimurium. Os dois primeiros agentes são importantes para à saúde das aves, enquanto os dois últimos são importantes quando se refere à saúde pública. Os primeiros relatos das bactérias do gênero Salmonella sp. ocorreram em 1880, quando foram descobertas por Erberth. Cinco anos mais tarde, Smith e Salmon caracterizaram o gênero Salmonella sp. chamando-o de Bacillus cholerasuis, a partir de suínos com mesmo quadro clínico de gastroenterite observados em humanos por Erberth. Mas só em 1900 o gênero foi classificado como Salmonella sp. por Lignières.

Atualmente o gênero é dividido em duas espécies: Salmonella entérica contendo seis subespécies (enterica, salamae, arizonae, diazonae, houtenae e a indica) e Salmonella bongori. Muitos sorovares estão identificados atualmente, dentre estes a S. enterica subsp. enterica, inclui os de maior importância para a avicultura e para a saúde pública. Dentro da espécie Salmonella entérica subsp. enterica os sorovares que recebem maior atenção são: Pullorum, Gallinarum, e Enteritidis, por causarem prejuízos econômicos na avicultura mundial e doenças em humanos. A S. enterica subsp. enterica na sua grande maioria são isoladas de animais de sangue quente, e são responsáveis pela maioria das salmoneloses humanas. Esses microrganismos infectam as aves podendo causar três tipos de doenças diferentes: a pulorose (Salmonella pullorum), o tifo aviário (Salmonella gallinarum) e o paratifo aviário (demais sorotipos de Salmonella sp). Entretanto esses sorovares são bastante relacionados, Feng et al. (2013) citam que as diferenças genéticas refletem restrições relacionadas aos hospedeiros e que são tão similares que podem ser considerados uma variante da mesma bactéria. Portanto a salmonelose é uma das principais infecções bacterianas que afetam as aves comerciais, causando prejuízos à produção avícola, bem como sendo um 
problema de saúde pública (Nabil et al., 2018; Zanetti et al., 2019). Além disso a Salmonella é um importante patógeno zoonótico de origem alimentar, e a carne de frango é considerada uma de suas principais fontes (Ziba et al., 2020).

\section{Metodologia}

Para alcançar os objetivos deste artigo, foi realizada uma pesquisa bibliográfica, com o propósito de caracterizar a Salmonelose aviária, em seus vários aspectos, bem como a sua presença no Brasil. Foram analisados referenciais teóricos publicados em livros e revistas científicas (artigos), preferencialmente nos últimos dez anos. Os artigos foram selecionados a partir das seguintes palavras-chave: Salmonella, aves, Brasil, Salmonelose. Foram utilizadas as Plataformas de Pesquisa PUBMED, CAPES, Scholar google, Sciencediretc e Scientific Electronic Library Online (SciElo). Eliminaram -se as revisões de literatura simples, os estudos indisponíveis e os que não abordaram o tema em questão. Após leitura crítica de títulos e resumos, foram incluídos 68 estudos, na sua maioria em língua inglesa.

\section{Histórico e Etiologia}

O tifo aviário foi descrito pela primeira vez em 1889 na Inglaterra por Klein. A enfermidade foi confundida com a cólera aviária e febre tifoide humana, e para evitar esse tipo de confusão a doença ficou denominada como tifo aviário (Berchieri e Freitas, 2015). A Salmonella entérica subespécie entérica sorotipo Gallinarum (SG) é o agente etiológico causal do tifo aviário ou da febre tifoide das aves domésticas (Seo et al., 2019). Pouco tempo depois em 1899 Rettger relatou, pela primeira vez, o agente causador da pulorose, e em 1909 o mesmo pesquisador denominou o agente como Bacteruim pullorum. Posteriormente essa denominação foi mudada para Salmonella pullorum. A Salmonella enterica subespécie enterica sorotipo Pullorum (SP) é o agente etiológico causador da doença aviária pulorose conhecida como diarreia bacilar branca ou diarreia branca (Chen et al., 2020).

Com relação às outras Salmonellas, causadoras do paratifo aviário, existem relatos da década de 80 de que esta doença já eram um grande problema, tanto na produção avícola como na saúde pública, em países desenvolvidos como Europa e Estados Unidos. No Brasil os primeiros surtos da doença datam da década de 90. Nessa época o Brasil já importava material genético principalmente dos EUA onde era grave o problema de salmoneloses em aves e humanos. A Salmonella corresponde como uma das principais doenças transmitidas por alimento do mundo, sendo responsável por mais de $30 \%$ das doenças alimentares do Brasil de acordo com o Ministério da Saúde (Brasil, 2018).

\section{Epidemiologia}

A ingestão de carne de frango tem aumentado progressivamente, é a segunda carne mais consumida no mundo e é considerada a mais consumida no Brasil (FAO, 2015). A alta demanda por esse produto, proporciona o desenvolvimento e a consolidação da indústria avícola em vários países, como no Brasil, líder na exportação e produção de carne de frango.

A pulorose é uma doença de distribuição mundial. É considerada erradicada de aves de produção de muitos países desenvolvidos como Europa Ocidental, Estados Unidos da América, Canadá, Austrália e Japão, onde os programas de controle e prevenção são executados de forma contínua e rigorosa. Os relatos da pulorose, com perdas significativas para a avicultura (Li et al., 2018), são mais comuns em países em desenvolvimento como o México, América Latina, Oriente Médio, Índia e África. As galinhas e os perus recém-nascidos com doença sistêmica e os portadores, são as principais fontes de infecção. A S. pullorum apesar de ser mais específica de galinhas e perus pode se albergar em outras aves como marrecos, gansos, faisões, codornas, papagaios, pardais e canários. Entretanto as galinhas são hospedeiros naturais do agente etiológico. Além disso, Wei et al. (2020) citam que as aves silvestres e migratórias podem ser reservatórios de Salmonelas patogênicas e resistentes, sendo 
um grande risco para aves alojadas em granjas bem como para a saúde pública. A S. pullorum deixa os animais infectados para alcançar um novo hospedeiro por meio das fezes contaminadas, que se espalham nas incubadoras e no aviário, nas instalações do criatório, nos vasilhames etc., contaminando portanto o ambiente. Sangue, órgãos, carcaças, cascas e fragmentos de ovos infectados também são via de eliminação do agente. Os pintainhos após a eclosão nascem molhados, e esse líquido presente ao nascimento também pode conter o agente.

A transmissão da doença pode acontecer de forma indireta por meio de solo, ar, alimentos, água de beber, vetores e fômites contaminados com o microrganismo. Mas o principal meio de transmissão do agente é a forma direta via vertical (transovariana). Os ovos se contaminam com o agente etiológico presente no intestino quando estes estão sendo formados, resultando em ovos inviáveis para a incubação. A transmissão horizontal do agente acontece por meio do contato físico entre as aves como no canibalismo, contato com aves mães, aves selvagens e pintinhos doentes no incubatório, no galpão e na caixa de transporte (Berchieri \& Freitas, 2015). A principal forma de penetração da bactéria no novo hospedeiro é por meio da via oral (via de infecção natural), através da ingestão de ração e água de beber contendo a bactéria.

O tifo aviário (S. galinarum) é uma enfermidade que se apresenta distribuída mundialmente, e que permanece sob controle em países desenvolvidos como Europa, Estados Unidos e Canadá. Apesar de controlada nos países desenvolvidos, o tifo aviário representa uma ameaça para as indústrias de países em desenvolvimento na América do Sul, Ásia e África Central. No Brasil apesar de considerada sob controle, surgiram relatos da sua ocorrência em várias regiões, provocando sérios problemas para a avicultura e despertando preocupação de produtores e órgãos fiscalizadores do país. Em Santa Catarina Gadotti et al. (2020) identificaram o mesmo perfil genotípico em 57,1\% dos isolados de S. gallinarum, de casos clínicos em frangos, sugerindo a ocorrência de um clone endêmico, cuja disseminação estava possivelmente ligada ao transporte de aves infectadas entre as regiões, entretanto esses mesmos autores relatam outros quinze perfis genotípicos, evidenciando a variabilidade genética de cepas circulantes e as múltiplas fontes de contaminação. No Brasil, apesar dos esforços de biossegurança, vários casos do sorotipo Gallinarum foram relatados nas últimas duas décadas. Houve 151 surtos oficialmente registrados entre 2005 e 2017 (OIE, 2020). Mais recentemente, surtos foram registrados, caracterizando o tifo aviário como doença ativa. Além disso, estes dados podem ser provavelmente subestimados, uma vez que vários casos podem não ter sido relatados as instituições oficiais. Os hospedeiros naturais do tifo aviário são as galinhas. Mas outros animais como os perus, aves caipiras e selvagens, angolas, e aves em geral também podem servir como fonte de infecção (Pal et al., 2017). Além disso, trabalhadores de granjas também podem transmitir a doença. A principal via de eliminação são as fezes contaminadas. Mas além das fezes, aves mortas no galpão podem disseminar a bactéria rapidamente no ambiente, bem como, filhotes mortos e doentes podem contaminar os compartimentos das incubadoras e nascedouros. $\mathrm{O}$ sangue proveniente do canibalismo entre as aves, e os ovos rachados, também podem servir como via de eliminação do agente etiológico.

Ao contrário da pulorose e do paratifo aviário, em que se destaca o meio de transmissão vertical, no tifo aviário o meio horizontal parece ser importante. A transmissão horizontal ocorre através do contato entre aves saudáveis com aves infectadas e mortas, pintinhos doentes ou sadios no caminhão, em incubatório e nascedouros, e através do canibalismo. A doença pode ser transmitida por meio do contato indireto através de moscas, água, ração, cama do aviário, fômites e matéria orgânica contaminada (Barancelli, Martin e Porto, 2012). A principal forma de acesso do agente etiológico no novo hospedeiro é através da via oral. Aves ingerem água, comida, fezes, poeira de superfície, cama contaminada e consequentemente se infectam.

Os sorotipos paratifóides estão mundialmente distribuídos, ocorrendo em qualquer local que haja atividade avícola e que dê condições para a sua multiplicação. A principal via de eliminação da bactéria são as fezes. Mas sangue, aves mortas no galpão, ambiente do incubatório, ovos com trincas ou qualquer outro material contaminado pode servir para disseminação do microrganismo (Andreatti Filho, 2006). O meio de transmissão pode ser tanto o indireto através de água, ração, fômites, ar, 
solo e vetores, como também o direto, tanto pela transmissão vertical como pela transmissão horizontal. Sendo que a transmissão vertical ou transovariana, é aquela em que o ovo se contamina no momento que está sendo formado no trato reprodutivo. A contaminação pode ocorrer no ovário, oviduto e na passagem pela cloaca (contato com as fezes). Rocha et al. (2003) relatam que a transmissão direta pela via horizontal, pode ocorrer entre aves contaminadas no galpão de corte, no galpão de reprodutores, no caminhão de transporte e em qualquer local que possibilite o contato entre as aves. Os pintinhos doentes podem transmitir a doença para os saudáveis no incubatório e nascedouro no momento da bicagem e quando são transferidos para a granja. A principal porta de entrada das salmonelas paratíficas é a via oral, através da ingestão da bactéria presente na cama do frango, água, ração e vasilhames. A porta de entrada também poderá ser pelo trato respiratório através da inalação de poeira. É comum pintinhos inalarem as bactérias presentes no ambiente de nascedouros e incubadoras. Além das portas de entradas já mencionadas outras podem ser utilizadas como cloaca e conjuntiva (Andreatti Filho, 2006).

A grande taxa de contaminação de carcaças pode ser devido aos meios de abate e processamento da carne. É comum que feiras e pequenos estabelecimentos comerciais não possuam a infraestrutura ideal para o abate, não reduzindo portanto a contaminação cruzada. Além disso, a evisceração manual pode aumentar o risco de contaminação por Salmonella spp. (Riviera-Perez et al., 2014).

\section{Hospedeiro Susceptíveis}

As aves susceptíveis são as galinhas e os perus. Entretanto, outras aves como faisões, codornas, papagaios, canários e pombos podem adquirir a doença. Já os palmípedes parecem ser os mais resistentes a Salmonella pullorum. Os pintinhos apresentando menos de três semanas de vida são os mais afetados. Enquanto as galinhas de linhagens mais leves são menos susceptíveis de contrair a doença comparada com as linhagens pesadas, podendo existir portanto linhagem mais resistentes a infecção (Li et al., 2018). Parvej et al. (2016) citam a presença de isolados de Salmonella Enterica sorovar Gallinarum (biovar Pullorum e Gallinarum) multirresistentes entre galinhas poedeiras saudáveis, caracterizando assim a possibilidade de reservatórios assintomáticos. Os mamíferos domésticos e selvagens também podem ser acometidos, porém atuam mais como reservatórios da bactéria, servindo como fonte de infecção para as aves de produção. O homem também é susceptível (Lebdah, 2017). A Salmonella paratífica está amplamente distribuída entre os hospedeiros, aves selvagens e de fundo de quintal, répteis, insetos vetores e mamíferos em geral, que podem servir de fonte de infecção para as aves de produção. De maneira geral pássaros, pombos, perus, papagaios, codornas, patos e gansos albergam o agente, sendo que a galinha doméstica é o principal hospedeiro natural (reservatório) do agente, e reconhecidamente a principal fonte de infecção para humanos.

\section{Sinais Clínicos}

É indicativo de pulorose, pintinhos, já desde os primeiros dias de vida, apresentando diarreia em grande quantidade, de cor branca podendo variar para branco-amarelada. A cloaca vai estar suja de fezes com penugens grudadas ao redor. Aves apáticas, debilitadas, anoréxicas, cansadas, com respiração difícil, empenamento ruim, queda das asas, sonolentas, com atraso no crescimento, amontoadas perto da fonte de calor, apresentando claudicação, conjuntivite, sinovites e cegueira também são indicativos da enfermidade (Haider et al., 2012; Wang et al., 2012). Já em aves adultas nem sempre os sinais clínicos serão de fácil observação, normalmente estas vão apresentar diminuição no consumo de ração, baixo ganho de peso, diminuição da fertilidade e baixa eclodibilidade dos ovos. Podem apresentar eriçamento das penas, crista pálida e retraída, além de diarreia branco-amarelada a amarelo-esverdeada, apatia e desidratação. As aves que resistem podem apresentar baixos índices zootécnicos, além de carrear o microrganismo servindo de fonte de infecção para outras aves. A morbidade e a mortalidade vão depender de fatores relacionados à idade, condição nutricional e estresse. Pode acontecer mortalidade em 100\% do plantel com 
grande prejuízo as aves entre duas e três semanas de idade. A taxa de morbidade geralmente e maior que a taxa de mortalidade, pois muitos animais se recuperam (Wang et al., 2012).

O tifo aviário é mais relacionado as aves adultas, mas há casos com alta mortalidade em pintinhos. A doença pode durar de 5 a 7 dias, podendo serem observados, anemia severa, fezes diarreicas amarelo-esverdeada, queda na produção de ovos, dificuldade respiratória, fraqueza, prostração, podendo levar também a septicemia (Gadotti et al., 2020). O plantel acometido pode apresentar ainda queda de penas e penas eriçadas. A mortalidade não ocorre de uma vez, ela tende a ser lenta, iniciando com o adoecimento de algumas aves, e morte de outras, e isso vai se repetindo até que o galpão seja totalmente acometido tornando a mortalidade acentuada.

Os sinais clínicos do paratifo não são característicos da doença e são facilmente confundidos com o da pulorose quando as aves jovens desenvolvem o quadro clínico. E possível perceber nas duas primeiras semanas de vida apatia, perda severa de apetite, emagrecimento, penas eriçadas, queda da asa, amontoamento próximo da fonte de aquecimento, fezes diarréicas esbranquiçadas e profusas, empastadas nas penas ao redor da cloaca, sonolência, sede intensa, edema de cabeça, retardo de crescimento, apatia, pintinhos amontoados, problemas respiratórios, cegueira, conjuntivite, claudicação e alterações nervosas. Em aves adultas os sinais da doença são menos frequentes, principalmente quando a doença só ocorreu na forma intestinal e não na forma septicêmica. Em situações estressantes a ave adulta pode chegar a desenvolver a forma septicêmica, podendo ser observados sinais como emagrecimento, diarreia e queda de postura (Lebdah, 2017).

\section{Diagnóstico}

Os achados anatomopatológicos variam com a idade das aves e com o quadro clínico da doença. Nas aves novas em quadros subagudos não se observam alterações nos órgãos. Já nos quadros agudos podem ser observados, hepatomegalia e esplenomegalia além de congestão de fígado, baço e rins. Pontos brancos a amarelados indicando necrose no fígado, pulmão, moela, trato digestivo, músculo do coração e no pâncreas. O coração pode apresentar uma configuração disforme com um pericárdio grosso com a presença de exsudato amarelado com fibrina. O intestino grosso pode apresentar conteúdo caseoso e as articulações afetadas podem apresentam um líquido amarelado viscoso (Kumari et al., 2013). Os achados encontrados nas aves adultas geralmente são mais relacionados ao trato reprodutivo. Os ovários e ovidutos podem estar com a forma alterada, diminuídos de tamanho, hemorrágicos, com bordas irregulares, contendo no seu interior material caseoso a necrosado. Pericardite é bastante comum de ser encontrada. Pontos esbranquiçados a amarelados indicando necrose podem ser observados no coração e testículos dos machos (Kumari et al., 2013). Além do diagnóstico clínico e histopatológico, o isolamento e a identificação bioquímica das salmonelas, bem como a sorologia para as espécies de interesse, juntamente com Elisa e PCR, são métodos de diagnóstico comumente realizados.

\section{Ocorrência de Isolados Avícolas no Brasil}

No Brasil, surtos de febre tifoide e pulorose têm sido relatados ao longo dos últimos 50 anos (De Carli et al., 2017). O microrganismo é amplamente distribuído pelo país, em Minas Gerais já foram relatadas as espécies S. minnesota, S. sandiego, S. schwarzengrund, S. infantis, S. hadar, S. enterica subsp. entérica (O: 4.5), S. montevidéu, S. miami, S. heidelberg, S. cerro, S. ndolo, S. panama, S. anatum, S. tennessee, S. agona, S. newport e S. muenster (Lúcio et al., 2019). Já no Paraná, Perin et al. (2020) pesquisando Salmonellas na carne de frango, identificaram principalmente S. Typhimurium e S. Heidelberg. Neste mesmo estudo um total de $85,7 \%$ dos isolados foram identificados com um perfil multirresistente, e alguns apresentaram genes codificadores de beta-lactamase de espectro estendido (ESBL), especialmente blaCTX-M-2 e blaTEM-1. Voss-Rech et al. (2019) citam que na região sul do Brasil, a maior área produtora de carne de frango, há a predominância da S. Heidelberg, 
destacando-se pela sua resistência e manutenção no ambiente, reforçando a necessidade de melhorar as medidas de prevenção e gestão dos dejetos nas granjas. Ainda na região sul, estudos identificaram entre 5\% (Voss-Rech et al., 2015) e 11\% (Pandini et al., 2015) de amostras para Salmonella não tifóide de origem aviária, S. Heidelberg, S. Hadar, S. Typhimurium, S. Mbandaka, S. Newport, S. Infantis e S. Senftenberg foram os mais comuns (Pulido-Landínez et al., 2013; Pandini et al., 2015; Voss-Rech et al., 2015). Salmonella Infantis é frequentemente associada a infecções humanas sendo transmitida pelo consumo de alimentos contaminados, principalmente a carne de frango. Foram relatados isolados no estado de São Paulo e Mato Grosso do Sul, presentes tanto em frigoríficos quanto nas granjas, e com potencial capacidade de produzir biofilmes (Mendonça et al., 2020).

Monte et al. (2019) citam que no Brasil no período entre 2000-2016, a ocorrência e a persistência de linhagens internacionais de sorovares de S. entérica, na cadeia de produção de alimentos (aves e suínos), foram sustentadas por genomas conservados e amplos virulomas e resistomas. Além disso, a análise filogenética revelou múltiplas linhagens independentes, tais como S. enterica serovares S. Infantis, S. Schwarzengrund, S. Minnesota, S. Kentucky e S. Brandenburg. Já Moreno et al. (2019) relataram a presença de Salmonella enterica sorovar Schwarzengrund, portadora do gene mcr-1 (um importante marcador para resistência a colistina), na carne de frango no Brasil. Wibisono et al. (2020) citam que dentre os antibióticos utilizados nas granjas a combinação amoxicilina + colistina é uma das mais utilizadas. Penha Filho et al. (2016) estudando a resistência antimicrobiana de isolados obtidos em surtos de tifo aviário e pulorose no Brasil, destacam uma alta sensibilidade aos antibióticos tetracilina e aos $\beta$-lactâmicos, entretanto citam que a resistência às quinolonas e as fluoroquinolonas aumentou ao longo do tempo. Com relação a resistência e sorogrupo Costa et al. (2013) em seu trabalho, analisando 12.582 isolados de carcaças e produtos avícolas de diversas regiões do Brasil, relatam que os sorogrupos mais prevalentes de Salmonella enterica foram O:4, O:9, O:21 e O:7; já os sorovares mais prevalentes foram Enteritidis, Minnesota, Typhimurium, Schwarzengrund e Mbandaka. Neste mesmo estudo foi observada multirresistência (três ou mais classes) em 16,4\% dos isolados.

De Carli et al. (2017) citam, que os atuais surtos de febre tifoide no Brasil estão provavelmente relacionados às falhas dos programas de biossegurança nas granjas em controlar a disseminação de cepas locais, e que é provável que a indústria e os serviços veterinários governamentais não tenham sido capazes de responder adequadamente ao enorme aumento na produção avícola brasileira, bem como as medidas de biossegurança podem não ter sido tão rigorosas como resultado desse aumento. Reforçando assim a importância da vigilância epidemiológica como subsídio às políticas de saúde animal.

Logicamente que novos sorotipos de Salmonella podem surgir devido a mudanças ambientais nas granjas ou devido à novas e mais precisas formas de identificação laboratorial. A presença de sorotipos incomuns de Salmonella em aves (sorotipos emergentes e reemergentes) pode causar doenças nas aves e pode não ser fácil determinar quais medidas de controle adequadas precisam ser tomadas. Vários desses sorotipos incomuns, sendo transmitidos por alimentos, também podem causar doenças na população humana. Portanto, sorotipos emergentes de Salmonella que causam doença em frangos de corte podem ser considerados uma causa potencial de outros problemas de saúde pública (Pulido-Landínez et al., 2013; Pulido-Landínez et al., 2019).

\section{Saúde Pública, Prevenção e Controle}

Este microrganismo pode causar salmonelose também em humanos, e é categorizada como uma importante zoonose em saúde pública. Isolados de Salmonella multirresistentes com alta adaptabilidade, têm sido responsáveis por muitos surtos de doenças transmitidas por alimentos (Xu et al., 2020). A infecção pode ser adquirida por contato direto e indireto com os animais. A transmissão indireta pode ocorrer pelo contato com o meio ambiente dos animais ou com objetos contaminados ao redor das granjas. A salmonelose em humanos pode ser de três tipos, a febre tifóide, a febre paratifóide e a salmonelose não tifóide. A febre tifóide e a febre paratifóide são causadas por S. typhi e S. enterica serovar Paratyphi (S. paratyphi), em 
contraste, S. typhimurium, S. enteritidis, Salmonella enterica serovar newport (S. newport) e Salmonella enterica serovar heidelberg (S. heildeberg) causam as infecções não tifóides (Wibisono et al., 2020). Os microorganismos patogênicos em alimentos são transmitidos aos humanos por meio de uma variedade de produtos, como aves e ovos (Ximenes et al., 2019), e a contaminação pode ocorrer em todas as fases da produção, afetando portanto a qualidade destes alimentos. Lee et al. (2013), por exemplo, detectaram significativa presença de Salmonella Gallinarum em ovos, principalmente oriundos de sistemas orgânicos de produção.

Desde a descoberta destas doenças, muitos esforços têm sido feitos para controlar e prevenir sua ocorrência na criação comercial de aves. No entanto, elas permanecem um sério problema econômico para a avicultura em países onde as medidas de controle não são eficientes ou naqueles onde as condições climáticas favorecem a disseminação ambiental das Salmonellas (Barrow e Neto, 2011). Além disso, quando se trata de salmoneloses, o controle da doença é difícil devido a complexa epidemiologia e a vasta variedade de sorovares sem hospedeiros específicos que possibilitam inúmeros reservatórios e diferentes fontes de contaminação (Foley et al., 2013).

Para aumentar a resistência dos frangos a doenças, é necessário levar em consideração as melhorias genéticas (Li et al., 2018; Jajere et al., 2019), uma saúde intestinal ideal, excelente saúde do sistema respiratório, bem-estar animal e a biossegurança (Pulido-Landinez (2019). O uso de antimicrobianos é a estratégia comum de tratamento e prevenção de doenças intestinais em aves, entretanto seu uso tem efeito não apenas nos patógenos mas também sobre todo o equilíbrio da microbiota intestinal. Sabe-se que a transferência horizontal de genes relacionados a resistência antimicrobiana ocorre entre população bacterianas presentes no intestino das aves, dentre elas a Salmonela (Oladeinde et al. 2019). Podendo portanto produzir um estado de disbiose neste local. Além disso, existe atualmente um impacto muito grande no ambiente devido ao uso dos antimicrobianos em larga escala, na produção animal, não podemos esquecer que resíduos antimicrobianos são poluentes ambientais. Estes aspectos, levam portanto o controle da salmonelose aviária para formas alternativas de prevenção.

Portanto, o uso de antibióticos como promotores de crescimento na avicultura enfatizou a necessidade de alternativas que possam pelo menos manter desempenhos semelhantes. Essas alternativas podem incluir, probióticos, prebióticos e extratos de plantas (Huyghebaert et al., 2011; Hernandez-Patlan et al., 2018); bacteriófagos (Andreatti Filho et al., 2007); ácidos orgânicos (Menconi et al., 2011; Hernandez-Patlan et al., 2018). Outros compostos estudados, como o zinco + clinoptilolita teve efeito protetor em frangos de corte desafiados com S. pullorum, sendo uma opção como um novo agente antibacteriano na ração (Wang et al. 2012).

Manipular a microbiota intestinal das aves, sem dúvida, é uma estratégia de controle, pois serviria como paradigma terapêutico promissor; embora não seja um novo conceito para a indústria avícola, pois já foi observado, que galinhas recémnascidas podem ser protegidas, contra a colonização por Salmonella enteritidis, por administração de uma suspensão do conteúdo intestinal derivada de frangos adultos saudáveis (Kogut, 2019).

Os prebióticos são definidos como componentes alimentares que conferem um benefício à saúde do hospedeiro associado à modulação de sua microbiota. Existem critérios específicos para que um componente alimentar seja considerado um prebiótico: devem ser resistentes tanto a hidrólise quanto a absorção pela parte superior do intestino, a fim de se moverem para o intestino inferior, onde residem os organismos-alvo e devem ser substratos apenas para os microrganismos a que se destinam, não sendo disponíveis para o hospedeiro (Pineiro et al., 2008). Já os probióticos, uma boa alternativa na manipulação da microbiota intestinal, são microrganismos vivos que, quando administrados em quantidades adequadas, conferem um benefício à saúde do hospedeiro. Podem ser bactérias incluindo Bacillus, Lactobacillus, Bifidobacterium, bem como leveduras (Saccharomyces cerevisiae) (Roberts et al., 2015; Joerger e Ganguly, 2017). Chen et al. (2020), estudando o efeito de um probiótico na saúde intestinal de pintinhos, relataram que o Lactobacillus paracasei KL1 e Lactobacillus plantarum subsp. plantarum reduziram efetivamente a mortalidade por pulorose nas aves jovens, promoveram o crescimento e o desempenho, 
regularam e equilibraram a microbiota intestinal, melhoraram a função imunológica, e evitaram a pulorose de pintinhos após a infecção. Os probióticos parecem ter vários mecanismos de ação incluindo a exclusão competitiva de bactérias patogênicas, melhora da resposta imune, função de barreira intestinal ajustada, produção de bacteriocinas e melhora da homeostase da microbiota (Gaggia et al., 2010). Uma alternativa, os simbióticos, são definidos como suplementos nutricionais combinando prebióticos e probióticos que seriam mais eficazes do que qualquer um utilizado sozinho. A principal razão para usar um simbiótico é que um probiótico, sem uma fonte de alimento prebiótico, não sobreviveria eficazmente no intestino. O uso de enzimas exógenas, como b-glucanase, xilanase, amilase, b-galactosidase, protease, lipase, fitase e b-mananase, também vem sendo utilizado na dieta para modular a resposta da microbiota intestinal das aves, com resultados promissores (Roberts et al., 2015; Kogut, 2019). Em seu estudo Shanmugasundaram et al. (2019) identificaram que o uso de simbióticos diminuiu a proliferação de Salmonella enterica ser. Enteritidis in vitro e diminuiu sua carga no conteúdo cecal e na carcaça dos frangos.

O uso de bacteriófagos protegidos, contra a desativação intestinal, fornece um produto que pode ser viável para a aplicação com a ração animal como alternativa antibiótica em frangos, pois a sua especificidade e ação potencial na manutenção da microbiota normal ajudariam na manutenção de um estado de saúde na ave (Chatain-Ly, 2014; Ma et al., 2016). Com relação as salmonelas aviárias, bacteriófagos foram capazes de parar completamente o crescimento de $S$. kentucky in vitro, sugerindo que os fagos têm um alto potencial para aplicação no controle de sorovares de Salmonella isolados de frangos de corte (Mahmoud et al., 2018). Em seu trabalho Bao et al., (2011) também demonstraram que bacteriófagos podem ter potencial para ser bons agentes terapêuticos e profiláticos no controle de infecções bacterianas em frangos por Salmonella Pullorum. Além disso Nabil et al. (2018) demonstraram que o tratamento com bacteriófagos foi eficaz na redução da colonização por S. typhimurium e S. enteritidis em frangos de corte e pode ser usado como uma alternativa aos antibióticos.

Sistemas orgânicos, alternativos de produção, também tem se intensificado no mundo inteiro. Entretanto, estimativas de prevalência para Salmonella sp. têm sido semelhantes para ambos os tipos de produção (orgânica e convencional), para amostras ambientais e amostras de varejo (Golden \& Mishra, 2020). Além disso, Park et al. (2017) em seu estudo demonstraram que mesmo na carne de frango oriunda de sistemas de produção livres de antibióticos, foram encontrados isolados ESBL (produtores de beta-lactamases de espectro extendido) entre as Salmonellas. E que seus genes, eram os mesmos daqueles isolados encontrados na carne de frango oriunda de sistemas convencionais. Outro estudo também demostrou uma maior contaminação por Salmonella Gallinarum em ovos produzidos em sistemas orgânicos de produção (Lee et al., 2013). Portanto, Jajere et al. (2019) citam que em criações não comerciais é importante armazenar a ração e a água em recipientes cobertos e melhorar a biossegurança, para reduzir assim o acesso de pássaros e animais selvagens.

Diversas medidas podem ser usadas para prevenir e controlar infecções por Salmonella em aves, entretanto a vacinação é a medida mais prática porque evita a contaminação dos alimentos e previne doenças em humanos. As vacinas de Salmonella podem diminuir o risco inerente a saúde pública, reduzindo a colonização e a invasão nas aves, incluindo a invasão de tecidos reprodutivos, e diminuindo a eliminação fecal e a contaminação ambiental. Uma boa vacina deve ser administrada via água de bebida, simulando uma infecção natural e estimulando as respostas imunológicas sistêmicas e de mucosas. Além disso, uma vacina viva ideal para controlar Salmonella em frangos comerciais deve gerar proteção contra várias cepas (Penha Filho et al., 2010). Os pintinhos devem ser vacinados no incubatório ou no nascimento, obtendo proteção contra desafios de campo nas primeiras semanas de vida. A vantagem adicional da administração oral na produção avícola é apoiada pelo fato de que a vacinação oral também contribui para a garantia de qualidade dos programas relacionados ao bem-estar animal, bem como diminui os custos. Além disso, vacinas multivalentes podem ser construídas com base no conhecimento das interações da bactéria com os hospedeiros específicos, evidenciando-se na expressão de virulência das cepas mais prevalentes na região (Revolledo e Ferreira, 2012). Entretanto, é de fundamental importância o monitoramento contínuo da eficiência das vacinas nas granjas (Lee et al., 2013). 
Perin et al., (2020) ainda reforçam que o monitoramento contínuo da ocorrência e resistência antimicrobiana de Salmonella em alimentos é necessário devido às implicações desse patógeno para a saúde pública e ao potencial de disseminação de isolados resistentes a antimicrobianos. E o controle se faz necessário em toda a cadeia produtora. PulidoLandinez (2019) pontua que todas as intervenções em granjas de matrizes, incubatórios, fábricas de ração e granjas de frangos de corte relacionadas ao controle de Salmonella terão um papel crucial no cumprimento dos objetivos nos abatedourosfrigoríficos. Pois o frango como matéria prima é portador de uma qualidade microbiológica intrínseca. Portanto, o controle e as intervenções estabelecidas em cada etapa da integração vertical, contribuirão para a redução da presença indesejada de Salmonella no produto. O controle ambiental e a biossegurança têm um papel fundamental, aja visto que muitas vezes isolados patogênicos, encontrados nas aves alojadas, adentraram as granjas não pelas matrizes mas pelo ambiente (Sever et al., 2019).

Pode haver diferenças dentro e entre as granjas quanto ao perfil de resistência aos antibióticos de Salmonella, algumas dessas diferenças podem estar relacionadas a sorovares específicos. No entanto, as diferenças entre as ganjas não foram associadas ao uso de antibióticos (Liljebjelke et al., 2017). Entretanto, Zhao et al. (2020) analisando a prevalência de Salmonellas em criações intensivas de frangos de corte na China, relatam uma grande quantidade de isolados multirresistentes portadores de genes relacionados a resistência aos antibióticos beta-lactâmicos (bla quinolones (aac(6')-Ib-cr, oqxB, qnrB e qnrD), enfatizando que o controle rigoroso do uso de antibióticos nas granjas, bem como o controle da presença de Salmonella nas aves são medidas de vital importância para a saúde pública.

Já Romero-Barrios et al. (2020) relatam que os níveis de resistência podem ser semelhantes nos diferentes setores amostrados ao longo da cadeia alimentar (por exemplo, matadouro e varejo) e os tipos de produto amostrado. Sugere-se que a prevenção da transmissão vertical de Salmonella resistente a antibióticos reduziria a contaminação das carcaças com Salmonella e, subsequentemente, a exposição humana. Portanto, a consolidação e o crescimento das integrações verticais em diversos países têm desempenhado um papel preponderante na diminuição ou no aumento da presença de Salmonella na carne de frango (Liljebjelke et al., 2017). Gong et al. (2013), pesquisando isolados de Salmonella Pullorum na China entre 19632010, demonstraram que o nível de resistência aos medicamentos está aumentando com o tempo, acentuadamente de 1990 para cá, e que esta resistência está associada a posse de integrons de classe 1 entre os isolados. Já Seo et al. (2019) em sua pesquisa na Coréia do Sul, detectaram preocupantes índices de resistência ao ácido nalidíxico, gentamicina, ciprofloxacina e ampicilina, em isolados de casos clínicos em galinhas, e que estes índices vêm aumentando ao longo do tempo. Evidenciando diferenças regionais quanto ao perfil das Salmonellas resistentes Kumari et al. (2013) citam, por exemplo, a alta sensibilidade a anfotericina B e ao cloranfenicol em seus isolados.

Xu et al. (2020) pontuam que a análise de risco do sistema de pontos críticos de controle (HACCP), para toda a cadeia alimentar de varejo de carne, deve ser analisada e melhorada a fim de evitar-se a contaminação cruzada na comercialização dos alimentos. Importante também que o monitoramento "presença-ausência" seja feito não somente por métodos moleculares (riscos de falsos positivos) mas também seja confirmado pelos métodos tradicionais de bacteriologia. Monitoramento constante e identificação de sorotipos específicos de Salmonella são cruciais para a formulação de esquemas de controle apropriados (Guard et al., 2012).

\section{Conclusão}

A salmonelose aviária é uma enfermidade de grande importância e a melhor forma de manter a saúde das aves é por meio de medidas de controle e prevenção corretas, rigorosas e contínuas no plantel. E sem um programa de biossegurança sistemático, é impossível que os países erradiquem ou pelo menos controlem a doença. Apesar de ser o ramo do agronegócio que mais investe em tecnologias para monitorar os aviários, a salmonelose ainda continua sendo uma ameaça para a avicultura e uma preocupação para a saúde pública. Responsável por provocar alta mortalidade e morbidade em aves domésticas, 
fechamento de granjas e embargos nas exportações, ainda é responsável pela maioria dos quadros de intoxicação alimentar na população mundial. A enfermidade apresenta uma série de sinais clínicos inespecíficos que podem ser confundidos com outras bacterioses. Por esse motivo é fundamental que antes de qualquer atitude a ser tomada em relação ao tratamento, o correto diagnóstico é fundamental. Medidas de manejo e higiene sempre serão as melhores opções. O Brasil atualmente ocupa uma posição elevada e respeitada na produção de frangos de corte e isso é devido principalmente à condição sanitária de seus produtos, o país atende um mercado consumidor cada vez mais exigente e é de responsabilidade do médico veterinário, dos produtores e de órgãos fiscalizadores atentar para a sanidade das aves, consequentemente garantindo segurança alimentar tanto para o mercado interno como para o exterior.

\section{Referências}

Andreatti Filho, R. L. Paratifo aviário. Saúde aviária e doenças. Rocca, 2006.

Andreatti Filho, R. L., Higgins, J. P., Higgins, S. E., Gaona, G., Wolfenden, A. D., Tellez, G., \& Hargis, B. M. (2007). Ability of bacteriophages isolated from different sources to reduce Salmonella enterica serovar Enteritidis in vitro and in vivo. Poultry science, 86(9), 1904-1909.

Bao, H., Zhang, H., \& Wang, R. (2011). Isolation and characterization of bacteriophages of Salmonella enterica serovar Pullorum. Poultry science, 90(10), 2370-2377.

Barancelli, G. V., Martin, J. G. P., \& Porto, E. (2012). Salmonella em ovos: relação entre produção e consumo seguro. Segurança Alimentar e Nutricional, 19(2), 73-82.

Barrow, P. A., \& Neto, O. F. (2011). Pullorum disease and fowl typhoid-new thoughts on old diseases: a review. Avian pathology, 40(1), 1-13.

Berchieri Jr, A., \& Freitas Neto, O. C. (2000). Salmoneloses aviárias. Doenças das aves, 185-195.

Brasil. Ministry of Health (2018). Foodborne diseases outbreaks in Brazil. Secretary of Health Surveillance, Brasília, Distrito Federal. http://portalarquivos2.saude.gov.br/images/pdf/2018/janeiro/1 7/Apresentacao-Surtos-DTA-2018.pdf

CHATAIN-LY, M. H. (2014). The factors affecting effectiveness of treatment in phages therapy. Frontiers in microbiology, 5, 51.

Chen, C., Li, J., Zhang, H., Xie, Y., Xiong, L., Liu, H., \& Wang, F. (2020). Effects of a probiotic on the growth performance, intestinal flora, and immune function of chicks infected with Salmonella pullorum. Poultry Science, 99(11), 5316-5323.

Costa, R. G., Festivo, M. L., Araujo, M. S., Reis, E. M., Lázaro, N. S., \& Rodrigues, D. P. (2013). Antimicrobial susceptibility and serovars of Salmonella circulating in commercial poultry carcasses and poultry products in Brazil. Journal of food protection, 76(12), 2011-2017.

De Carli, S., Gräf, T., Kipper, D., Lehmann, F. K. M., Zanetti, N., Siqueira, F. M., \& Lunge, V. R. (2017). Molecular and phylogenetic analyses of Salmonella Gallinarum trace the origin and diversification of recent outbreaks of fowl typhoid in poultry farms. Veterinary microbiology, $212,80-86$.

FAO. Food and agriculture organization of the united nations - fao. agriculture outlook 2015. (20a ed.), oecd-fao publishing, 2015. 148 p. available at: www.fao.org/3/a-i4738e.pdf.

Feng, Y., Johnston, R. N., Liu, G. R., \& Liu, S. L. (2013). Genomic comparison between Salmonella Gallinarum and Pullorum: differential pseudogene formation under common host restriction. PLoS One, 8(3), e59427.

Foley, S. L., Johnson, T. J., Ricke, S. C., Nayak, R., \& Danzeisen, J. (2013). Salmonella pathogenicity and host adaptation in chicken-associated serovars. Microbiology and Molecular Biology Reviews, 77(4), 582-607.

Gadotti, D. L., Maciel, P. B., Rebelatto, R., Duarte, S. C., \& Dezen, D. (2020). Genotypic diversity of Salmonella ser. Gallinarum strains isolated from 2012 to 2016 in Brazil. Turkish Journal of Veterinary and Animal Sciences, 44(1), 146-150.

Gaggìa, F., Mattarelli, P., \& Biavati, B. (2010). Probiotics and prebiotics in animal feeding for safe food production. International journal of food microbiology, 141, S15-S28.

Golden, C. E., \& Mishra, A. (2020). Prevalence of Salmonella and Campylobacter spp. in Alternative and Conventionally Produced Chicken in the United States: A Systematic Review and Meta-Analysis. Journal of food protection, 83(7), 1181-1197.

Gong, J., Xu, M., Zhu, C., Miao, J., Liu, X., Xu, B., \& Jia, X. (2013). Antimicrobial resistance, presence of integrons and biofilm formation of Salmonella Pullorum isolates from eastern China (1962-2010). Avian Pathology, 42(3), 290-294.

Guard, J., Sanchez-Ingunza, R., Morales, C., Stewart, T., Liljebjelke, K., Van Kessel, J., \& Hinton Jr, A. (2012). Comparison of dkgB-linked intergenic sequence ribotyping to DNA microarray hybridization for assigning serotype to Salmonella enterica. FEMS microbiology letters, 337(1), 61-72.

Haider, M. G., Chowdhury, E. H., Ahmed, A. K. M., \& Hossain, M. M. (2012). Experimental pathogenesis of pullorum disease in chicks by local isolate of Salmonella Pullorum in Bangladesh. Journal of the Bangladesh Agricultural University, 10(452-2016-35560), 87-94. 
Hernandez-Patlan, D., Solis-Cruz, B., Pontin, K. P., Latorre, J. D., Baxter, M. F., Hernandez-Velasco, X., \& Tellez, G. (2018). Evaluation of a solid dispersion of curcumin with polyvinylpyrrolidone and boric acid against Salmonella Enteritidis infection and intestinal permeability in broiler chickens: A pilot study. Frontiers in microbiology, 9, 1289.

Huyghebaert, G., Ducatelle, R., \& Van Immerseel, F. (2011). An update on alternatives to antimicrobial growth promoters for broilers. The Veterinary Journal, 187(2), 182-188.

Kogut, M. H. (2019). The effect of microbiome modulation on the intestinal health of poultry. Animal feed science and technology, 250, 32-40.

Kumari, D., Mishra, S. K., \& Lather, D. (2013). Pathomicrobial studies on Salmonella Gallinarum infection in broiler chickens. Veterinary world, 6(10), 725.

Jajere, S. M., Hassan, L., Aziz, S. A., Zakaria, Z., Abu, J., Nordin, F., \& Faiz, N. M. (2019). Salmonella in native "village" chickens (Gallus domesticus): prevalence and risk factors from farms in South-Central Peninsular Malaysia. Poultry science, 98(11), 5961-5970.

Joerger, R. D., \& Ganguly, A. (2018). Current Status of the Preharvest Application of Pro-and Prebiotics to Farm Animals to Enhance the Microbial Safety of Animal Products. Preharvest Food Safety, 349-360.

Lebdah, M. A., Eid, A. A., Nasef, S. A., \& Hamad, E. M. (2017). Phenotypic and genotypic characterization of paratyphoid Salmonellae isolated from poultry in Delta Area-Egypt. Zagazig Veterinary Journal, 45(3), 262-272.

Lee, S. K., Chon, J. W., Song, K. Y., Hyeon, J. Y., Moon, J. S., \& Seo, K. H. (2013). Prevalence, characterization, and antimicrobial susceptibility of Salmonella Gallinarum isolated from eggs produced in conventional or organic farms in South Korea. Poultry science, 92(10), $2789-2797$.

Li, X., Nie, C., Zhang, Z., Wang, Q., Shao, P., Zhao, Q., \& Qu, L. (2018). Evaluation of genetic resistance to Salmonella Pullorum in three chicken lines. Poultry science, $97(3), 764-769$.

Liljebjelke, K. A., Hofacre, C. L., White, D. G., Ayers, S., Lee, M. D., \& Maurer, J. J. (2017). Diversity of antimicrobial resistance phenotypes in Salmonella isolated from commercial poultry farms. Frontiers in veterinary science, $4,96$.

Lúcio, C. J., Mathias, J. B., Júnior, C. M. L., Flores, S. J. V. S., \& Teixeira, F. M. X. A. (2019). Occurrence of salmonella spp. in broiler chicken feces in the central region of the state of Minas Gerais, Brazil. Revista de Patologia Tropical/Journal of Tropical Pathology, 48(2), 79-86.

Ma, Y. H., Islam, G. S., Wu, Y., Sabour, P. M., Chambers, J. R., Wang, Q., \& Griffiths, M. W. (2016). Temporal distribution of encapsulated bacteriophages during passage through the chick gastrointestinal tract. Poultry science, 95(12), 2911-2920.

Mahmoud, M., Askora, A., Barakat, A. B., Rabie, O. E. F., \& Hassan, S. E. (2018). Isolation and characterization of polyvalent bacteriophages infecting multi drug resistant Salmonella serovars isolated from broilers in Egypt. International journal of food microbiology, 266, 8-13.

Menconi, A., Wolfenden, A. D., Shivaramaiah, S., Terraes, J. C., Urbano, T., Kuttel, J., \& Tellez, G. (2011). Effect of lactic acid bacteria probiotic culture for the treatment of Salmonella enterica serovar Heidelberg in neonatal broiler chickens and turkey poults. Poultry science, 90(3), 561-565.

Mendonça, E. P., Melo, R. T., Oliveira, M. R., Monteiro, G. P., Peres, P. A., Fonseca, B. B., \& Rossi, D. A. (2020). Characteristics of virulence, resistance and genetic diversity of strains of Salmonella Infantis isolated from broiler chicken in Brazil. Pesquisa Veterinária Brasileira, 40(1), 29-38.

Monte, D. F., Lincopan, N., Berman, H., Cerdeira, L., Keelara, S., Thakur, S., \& Landgraf, M. (2019). Genomic features of high-priority Salmonella enterica serovars circulating in the food production chain, Brazil, 2000-2016. Scientific reports, 9(1), 1-12.

Moreno, L. Z., Gomes, V. T., Moreira, J., de Oliveira, C. H., Peres, B. P., Silva, A. P. S., \& Moreno, A. M. (2019). First report of mcr-1-harboring Salmonella enterica serovar Schwarzengrund isolated from poultry meat in Brazil. Diagnostic microbiology and infectious disease, 93(4), 376-379.

Nabil, N. M., Tawakol, M. M., \& Hassan, H. M. (2018). Assessing the impact of bacteriophages in the treatment of Salmonella in broiler chickens. Infection ecology \& epidemiology, 8(1), 1539056.

OIE. 2020. World Organisation for Animal Health- Disease information. http:// www.oie.int/wahis 2/public/wahid.php/Diseaseinformation/statusdetail

Oladeinde, A., Cook, K., Lakin, S. M., Woyda, R., Abdo, Z., Looft, T., \& Glenn, T. (2019). Horizontal gene transfer and acquired antibiotic resistance in Salmonella enterica Serovar Heidelberg following in vitro incubation in broiler ceca. Applied and environmental microbiology, 85(22).

Pal, S., Dey, S., Batabyal, K., Banerjee, A., Joardar, S. N., Samanta, I., \& Isore, D. P. (2017). Characterization of Salmonella Gallinarum isolates from backyard poultry by polymerase chain reaction detection of invasion (invA) and Salmonella plasmid virulence (spvC) genes. Veterinary world, $10(7), 814$.

Pandini, J. A., Pinto, F. G. D. S., Muller, J. M., Weber, L. D., \& Moura, A. C. D. (2015). Occurrence and antimicrobial resistance profile of Salmonella spp. serotypes isolated from poultry farms in Paraná, Brazil. Arquivos do Instituto Biológico, 82.

Park, J. H., Kim, H. S., Yim, J. H., Kim, Y. J., Kim, D. H., Chon, J. W., \& Seo, K. H. (2017). Comparison of the isolation rates and characteristics of Salmonella isolated from antibiotic-free and conventional chicken meat samples. Poultry science, 96(8), 2831-2838.

Parvej, M. S., Nazir, K. N. H., Rahman, M. B., Jahan, M., Khan, M. F. R., \& Rahman, M. (2016). Prevalence and characterization of multi-drug resistant Salmonella Enterica serovar Gallinarum biovar Pullorum and Gallinarum from chicken. Veterinary world, 9(1), 65.

Penha Filho, R. A. C., de Paiva, J. B., da Silva, M. D., de Almeida, A. M., \& Junior, A. B. (2010). Control of Salmonella Enteritidis and Salmonella Gallinarum in birds by using live vaccine candidate containing attenuated Salmonella Gallinarum mutant strain. Vaccine, 28(16), 2853-2859.

Penha Filho, R. A. C., Ferreira, J. C., Kanashiro, A. M. I., Darini, A. L. D. C., \& Berchieri Junior, A. (2016). Antimicrobial susceptibility of Salmonella Gallinarum and Salmonella Pullorum isolated from ill poultry in Brazil. Ciência Rural, 46(3), 513-518. 
Perin, A. P., Martins, B. T. F., Barreiros, M. A. B., Yamatogi, R. S., Nero, L. A., \& dos Santos Bersot, L. (2020). Occurrence, quantification, pulse types, and antimicrobial susceptibility of Salmonella sp. isolated from chicken meat in the state of Paraná, Brazil. Brazilian Journal of Microbiology, 51(1), 335-345.

Pineiro, M., Asp, N. G., Reid, G., Macfarlane, S., Morelli, L., Brunser, O., \& Tuohy, K. (2008). FAO Technical meeting on prebiotics. Journal of clinical gastroenterology, 42, S156-S159.

Pulido-Landínez, M., Sánchez-Ingunza, R., Guard, J., \& Nascimento, V. P. D. (2013). Assignment of serotype to S almonella enterica isolates obtained from poultry and their environment in southern Brazil. Letters in applied microbiology, 57(4), 288-294.

Pulido-Landínez, M. (2019). Food safety-Salmonella update in broilers. Animal Feed Science and Technology, 250, 53-58.

Revolledo, L., \& Ferreira, A. J. P. (2012). Current perspectives in avian salmonellosis: vaccines and immune mechanisms of protection. Journal of Applied Poultry Research, 21(2), 418-431.

Rivera-Pérez, W., Barquero-Calvo, E., \& Zamora-Sanabria, R. (2014). Salmonella contamination risk points in broiler carcasses during slaughter line processing. Journal of food protection, 77(12), 2031-2034.

Roberts, T., Wilson, J., Guthrie, A., Cookson, K., Vancraeynest, D., Schaeffer, J., \& Clark, S. (2015). New issues and science in broiler chicken intestinal health: Emerging technology and alternative interventions. Journal of Applied Poultry Research, 24(2), 257-266.

Rocha, P. T., Mesquita, A. J. D., Andrade, M. A., Louly, P. R., \& Nascimento, M. N. (2003). Salmonella spp. em forros de caixa de transporte e órgãos de pintos de um dia. Arquivo brasileiro de medicina veterinária e zootecnia, 55(6), 672-676.

Romero-Barrios, P., Deckert, A., Parmley, E. J., \& Leclair, D. (2020). Antimicrobial Resistance Profiles of Escherichia coli and Salmonella Isolates in Canadian Broiler Chickens and Their Products. Foodborne Pathogens and Disease, 17(11), 672-678.

Shanmugasundaram, R., Mortada, M., Cosby, D. E., Singh, M., Applegate, T. J., Syed, B., \& Selvaraj, R. K. (2019). Synbiotic supplementation to decrease Salmonella colonization in the intestine and carcass contamination in broiler birds. Plos one, 14(10), e0223577.

Seo, K. W., Kim, J. J., Mo, I. P., \& Lee, Y. J. (2019). Molecular characteristic of antimicrobial resistance of Salmonella Gallinarum isolates from chickens in Korea, 2014 to 2018. Poultry science, 98(11), 5416-5423.

Sever, N. K., \& Akan, M. (2019). Molecular analysis of virulence genes of Salmonella Infantis isolated from chickens and turkeys. Microbial pathogenesis, 126, 199-204.

Voss-Rech, D., Vaz, C. S., Alves, L., Coldebella, A., Leão, J. A., Rodrigues, D. P., \& Back, A. (2015). A temporal study of Salmonella enterica serotypes from broiler farms in Brazil. Poultry Science, 94(3), 433-441.

Voss-Rech, D., Kramer, B., Silva, V. S., Rebelatto, R., Abreu, P. G., Coldebella, A., \& Vaz, C. S. L. (2019). Longitudinal study reveals persistent environmental Salmonella Heidelberg in Brazilian broiler farms. Veterinary microbiology, 233, 118-123.

Wang, L. C., Zhang, T. T., Wen, C., Jiang, Z. Y., Wang, T., \& Zhou, Y. M. (2012). Protective effects of zinc-bearing clinoptilolite on broilers challenged withSalmonella pullorum. Poultry science, 91(8), 1838-1845.

Wei, B., Shang, K., Cha, S. Y., Zhang, J. F., Kang, M., \& Jang, H. K. (2020). Prevalence and potential risk of Salmonella enterica in migratory birds from South Korea. Veterinary Microbiology, 249, 108829.

Wibisono, F. M., Wibisono, F. J., Effendi, M. H., Plumeriastuti, H., Hidayatullah, A. R., Hartadi, E. B., \& Sofiana, E. D. (2020). A review of salmonellosis on poultry farms: public health importance. Systematic Reviews in Pharmacy, 11(9), 481-486.

Ximenes, E., Ku, S., Hoagland, L., \& Ladisch, M. R. (2019). Accelerated sample preparation for fast salmonella detection in poultry products. In Foodborne Bacterial Pathogens (pp. 3-20). Humana, New York, NY.

Xu, Z., Wang, M., Zhou, C., Gu, G., Liang, J., Hou, X., \& Wei, P. (2020). Prevalence and antimicrobial resistance of retail-meat-borne Salmonella in southern China during the years 2009-2016: The diversity of contamination and the resistance evolution of multidrug-resistant isolates. International Journal of Food Microbiology, 333, 108790.

Zanetti, N. S., De Carli, S., Souza, M. N., Lehmann, F. K. M., Kipper, D., Dias, K. K. R., \& Ikuta, N. (2019). Molecular Detection and Characterization of Salmonella Gallinarum From Poultry Farms in Brazil. Journal of Applied Poultry Research, 28(4), 1335-1341.

Zhao, X., Hu, M., Zhang, Q., Zhao, C., Zhang, Y., Li, L., \& Liu, Y. (2020). Characterization of integrons and antimicrobial resistance in Salmonella from broilers in Shandong, China. Poultry Science, 99(12), 7046-7054.

Ziba, M. W., Bowa, B., Romantini, R., Di Marzio, V., Marfoglia, C., Antoci, S., \& Pomilio, F. (2020). Occurrence and antimicrobial resistance of Salmonella spp. in broiler chicken neck skin from slaughterhouses in Zambia. Journal of Veterinary Medicine and Animal Health, 12(2), 85-90. 